\title{
Crack Analysis in Tension Roll of Leveler for Continuous Casting Equipment
}

\author{
Yuncai $X A^{1, a,{ }^{*}}$, Qingyun Meng ${ }^{2, b}$ \\ ${ }^{12}$ Department of Mechanical Engineering, Dalian Vocational Technical College, Dalian, Liaoning, \\ 116037, China

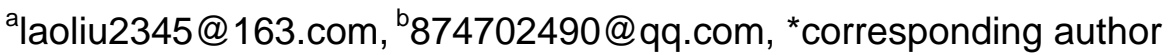

Keywords: Leveler, Roller, Crack Analysis

\begin{abstract}
The tension leveler is generally set after the billet guide and the secondary cooling device, continuous casting machine for continuously casting and straightening billet, another important function of the tension leveler is to transport the spindle. The opening degree of the upper and lower rolls can be conveniently adjusted by the tension leveler to meet the different sectional sizes of the casting blank. At the same time to be flexible speed regulation to adapt to the speed change. The rollers of the leveler require adequate hardness and wear resistance, generally through surfacing or spray welding treatment, in this paper, the crack occurred shortly after the roller assembly of the export American leveler was used, from heat treatment, forging material, surfacing layer hardness analysis, summarize the causes of cracks.
\end{abstract}

\section{Broken Roller Introduction}

The broken roller is located at the 42 position of the lower part of the tension leveler on the continuous casting line, roller chart number is 21066213, the assembly drawing is 21066175, chemical analysis experiment was carried out in Westmoreland Mechanical Testing and Research Laboratory, the company is a certified professional material analysis company, all analyses are carried out in accordance with the U. S. material testing standards (ASTM), the purpose of the test is: One is the formation of chemical analysis and mechanical performance testing documents; Two is the result of comparative analysis whether it meets the requirements of forgings in the fourth part of SN924; Three is the comparison of stainless steel surfacing layer meets the requirements of SN 925: 2005-04; The four is to determine the starting point of the damage.

The roll rupture originates from a single axial (length direction) crack, the crack extends to the length of the whole roll $(457 \mathrm{~mm})$, terminate on both sides of the bearing installation position. The bearings have been removed from the bore, in spite of this, probably due to crack expansion and deformation, the other side of the bearings can not be taken out. The crack on the roll is shown in Figure 1, the case where the crack extends into the roll is shown in Figure 2.

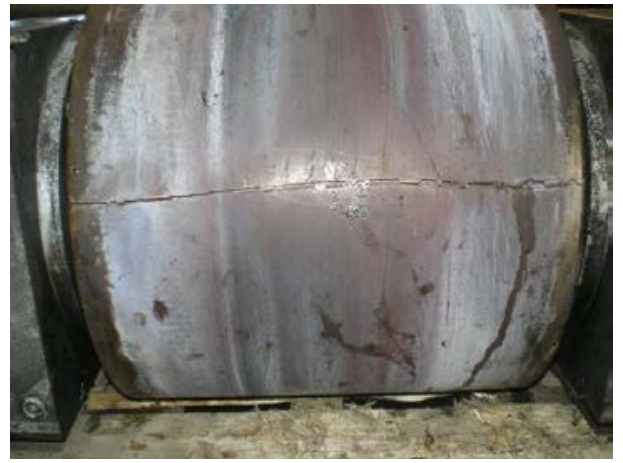

Fig.1. Longitudinal cracks on rollers

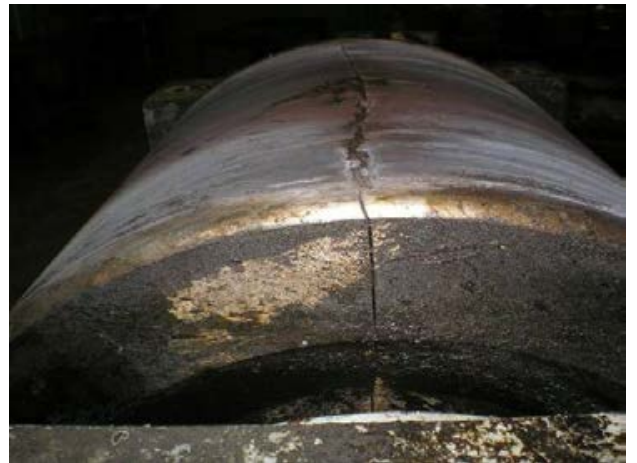

Fig.2. A crack extending inward

Take the bearings out of the roll, the extent of the crack extension can be observed on Figure 3, the red arrow indicates where the crack is. 


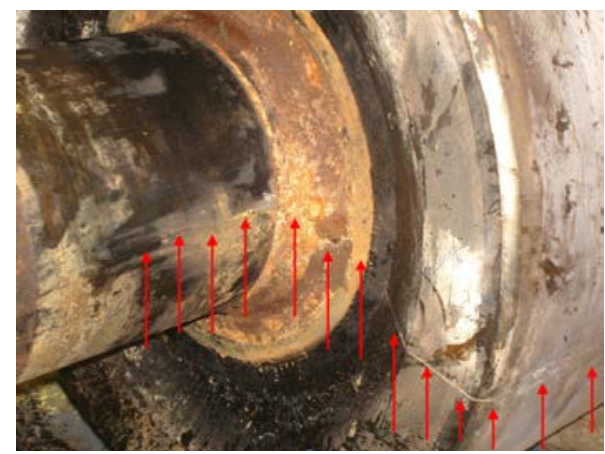

Fig.3. Crack in fitting zone / bearing mounting area

\section{The Removal of the Test Piece}

As shown in figure 4, the installation of the bearing at the outer end of the shaft and neck is cut by sawing, as shown in the red arrow, the crack extends to the cross section of the roll to the center hole, shaft neck mounted through both sides of bearing.

As shown in figure 5, cut off the part of the roller with a saw to avoid stress concentration, take two $25 \mathrm{~mm}$ thick $140 \mathrm{~mm}$ long test pieces, cut from a direction of 90 degrees from the direction of the crack, as shown in Figure 6; The two cuboid specimens and performance markings are shown in Figure 7, all tests are carried out at the radial 1/3 depth $(29.6 \mathrm{~mm})$ from the mounting surface of the bearing.

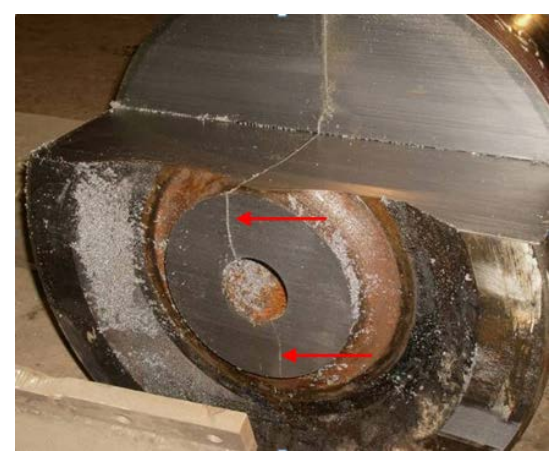

Fig.4. The crack passes through the roller section

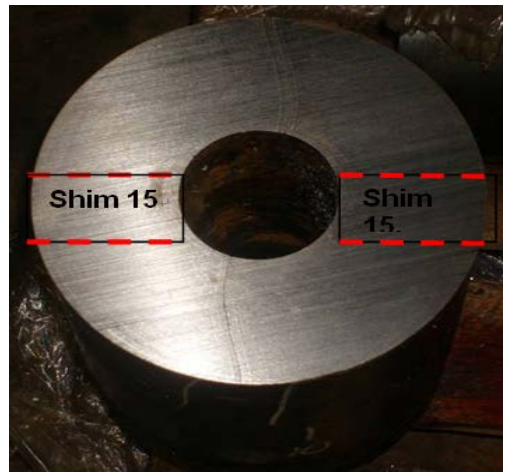

Fig.6. Test piece position

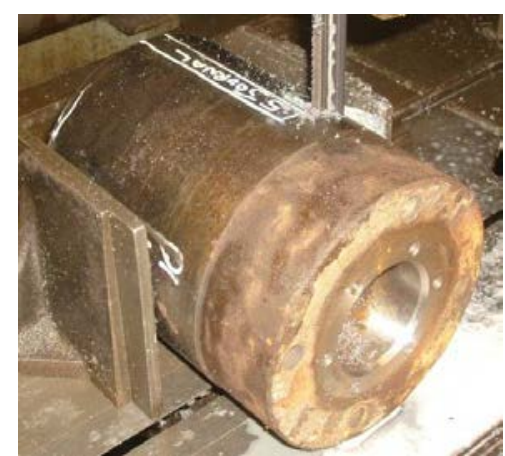

Fig.5. Interception of test pieces

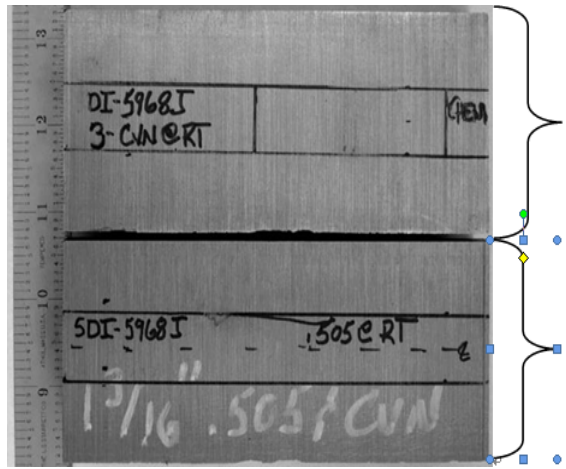

Fig.7. Stretch and impact parts

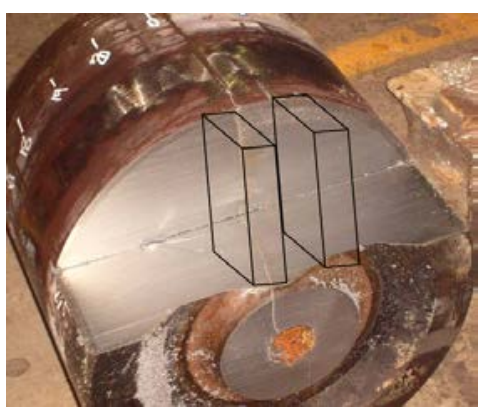

Fig.8. Cuboid specimen 
As shown in Figure 8: Cutting roller, take two cuboid specimens, 150mm long x 200mm deep x $25 \mathrm{~mm}$ thick, cut off, do crack analysis and do macroscopic (test piece) corrosion test, each specimen consists of a relatively cracked surface.

\section{Testing of Forgings}

Forge piece is made according to SN 924 Part 4, forging according to 21CrMoV5-11 conditioning condition and production.

Roller Transverse Stiffness. All hardness is read by Proceq Equotip-2 hardness tester. Read transverse hardness at two positions: The first position is about 3 inches $(76 \mathrm{~mm})$ from the edge of the roller, the angle from the crack to the radial depth of 9 inches $(228 \mathrm{~mm})$ is about 80 degrees; The second position is about 5-3/4 inches $(146 \mathrm{~mm})$ from the edge of the roller, the crack is close to the roller's radial depth of about 1 inches $(25.4 \mathrm{~mm})$, as shown in Figure 9, the yellow arrow indicates, the results are shown in Table 1 and Table 2. The hardness is converted to HV30 (Vivtorinox hardness) by ASTM E140 from HRc, it is found that the hardness is the same throughout the roll body depth, press HV30 (Vivtorinox hardness), the hardness at position 1 is $391 \mathrm{HV}$, the value at position 2 is $387 \mathrm{HV}$.

Press SN924, the fourth part is 220-265 HV. Readings are shown in Table 2, $12.7 \mathrm{~mm}$ said the hardness of surfacing layer, when the soft pressure corresponding to the limit of 3mm deep.

Shaft Neck Stiffness. The hardness of the surface of the shaft neck reading is transverse and circumferential direction, read horizontal hardness is from the surface depth is about $50.4 \mathrm{~mm}$, at about 90 degrees in the radial position of crack. The hardness of the circle is the three points of the shaft, each circle is separated by $90^{\circ}$ from 4 points, the 3 width is about 1 "(25.4mm), 4 "(102mm), and 7 "(178mm). The results are shown in tables 3 and 4, according to the fourth part of the SN924 hardness value is 220-265 HV.

The transverse hardness value in the whole depth is consistent, the average reading is $394 \mathrm{HV}$, the readings of surface hardness are similar, the average reading is $398 \mathrm{HV}$ at $25.4 \mathrm{~mm}, 415 \mathrm{HV}$ at $101 \mathrm{~mm}, 396 \mathrm{HV}$ at $178 \mathrm{~mm}$, according to the fourth part of the SN924 hardness value is $220-265$ HV.

Table 1: Lateral hardness at position 1 (near the shoulder)

\begin{tabular}{|c|c|c|c|c|c|c|c|c|c|c|c|c|}
\hline \multicolumn{2}{|c|}{ Depth (mm) } & 3.2 & 6.4 & 9.5 & 12.7 & 19.1 & 25.4 & 38.1 & 50.8 & 63.5 & 76.2 & 88.9 \\
\hline \multirow{2}{*}{ Hardness } & $\mathrm{HV}$ & 394 & 375 & 478 & 414 & 398 & 395 & 398 & 396 & 395 & 402 & 406 \\
\hline & HRC & 40.2 & 38.3 & 46.9 & 42.2 & 40.6 & 40.3 & 40.6 & 40.4 & 40.3 & 41.0 & 41.4 \\
\hline \multicolumn{2}{|c|}{ Depth (mm) } & 101.6 & 114.3 & 127 & 139.7 & 152.4 & 165.1 & 177.8 & 190.5 & 203.2 & 215.9 & 228.6 \\
\hline \multirow{2}{*}{ Hardness } & $\mathrm{HV}$ & 396 & 394 & 410 & 410 & 398 & 407 & 407 & 403 & 400 & 396 & 395 \\
\hline & HRC & 40.4 & 40.2 & 41.8 & 40.8 & 40.6 & 41.5 & 41.5 & 41.1 & 40.8 & 40.4 & 40.3 \\
\hline Average & $\begin{array}{c}\mathrm{HV} \\
\mathrm{HRC}\end{array}$ & $\begin{array}{c}391 \\
41.0\end{array}$ & & & & & & & & & & \\
\hline
\end{tabular}

Table 2: Lateral hardness at position 2 (Off-axis 5-3/4 "point)

\begin{tabular}{|l|c|c|c|c|c|}
\hline \multicolumn{2}{|c|}{ Surfacing Depth (mm) } & 0.0 & 3.2 & 6.4 & 9.5 \\
\hline \multirow{2}{*}{ Hardness } & HV & 323 & 378 & 356 & 388 \\
\cline { 2 - 6 } & HRC & 32.5 & 38.6 & 36.2 & 39.6 \\
\hline \multicolumn{2}{|l}{ Forging Depth (mm) } & 12.7 & 15.9 & 19.1 & 25.4 \\
\hline \multirow{2}{*}{ Hardness } & HV & 378 & 400 & 403 & 405 \\
\cline { 2 - 6 } & HRC & 38.6 & 40.8 & 41.1 & 41.1 \\
\hline
\end{tabular}

Table 3: Bearing mounting surface transverse hardness

\begin{tabular}{|c|c|c|c|c|c|c|c|c|c|c|c|}
\hline \multicolumn{2}{|c|}{ Depth (mm) } & 3.2 & 6.4 & 9.5 & 12.7 & 19.1 & 25.4 & 31.8 & 38.1 & 44.5 & 50.8 \\
\hline \multirow{2}{*}{$\begin{array}{c}\text { Hardnes } \\
\text { S }\end{array}$} & $\mathrm{HV}$ & 391 & 388 & 396 & 399 & 398 & 394 & 402 & 394 & 403 & 377 \\
\hline & HRC & 39.9 & 39.6 & 40.4 & 40.7 & 40.6 & 40.2 & 41 & 39.2 & 41.1 & 38.5 \\
\hline \multirow{2}{*}{ Average } & $\mathrm{HV}$ & 394 & & & & & & & & & \\
\hline & HRC & 40.1 & & & & & & & & & \\
\hline
\end{tabular}




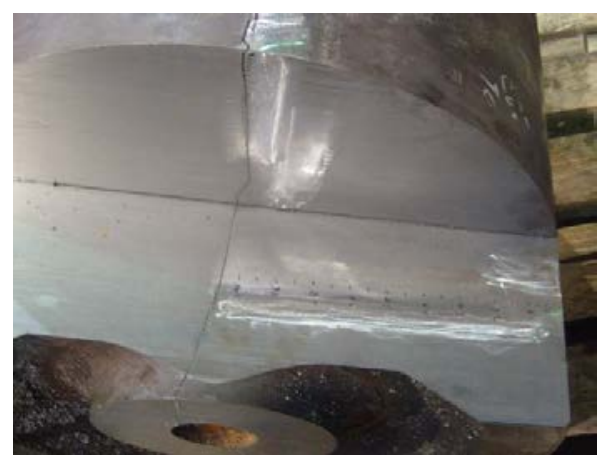

Fig.9. Lateral hardness position

Table 4: Surface hardness of bearing mounting surface (HV30)

\begin{tabular}{|c|c|c|c|c|c|c|}
\hline \multirow{2}{*}{$\begin{array}{c}\text { Radial } \\
\text { Position }\end{array}$} & \multicolumn{2}{|c|}{$\mathbf{2 5 . 4 m m}$ from Fillet } & \multicolumn{2}{|c|}{ 101mm from Fillet } & \multicolumn{2}{|c|}{ 178mm from Fillet } \\
\cline { 2 - 7 } & HV & HRC & HV & HRC & HV & HRC \\
\hline $0^{\circ}$ & 385 & 39.3 & 406 & 41.4 & 378 & 38.6 \\
\hline $90^{\circ}$ & 395 & 40.3 & 414 & 42.2 & 387 & 39.5 \\
\hline $180^{\circ}$ & 405 & 41.3 & 425 & 43.2 & 409 & 41.7 \\
\hline $270^{\circ}$ & 407 & 41.5 & 415 & 42.3 & 411 & 41.9 \\
\hline Avg & $\mathbf{3 9 8}$ & $\mathbf{4 0 . 6}$ & $\mathbf{4 1 5}$ & $\mathbf{4 2 . 3}$ & $\mathbf{3 9 6}$ & $\mathbf{4 0 . 4}$ \\
\hline
\end{tabular}

Chemical Composition. As shown in Table 5, confirm that the chemical composition of the roller base metal meets the requirements of 21CrMoV5-11.

Table 5: Chemical composition of forgings

\begin{tabular}{|c|c|c|c|c|c|c|c|c|c|c|c|}
\hline $\begin{array}{c}\text { Chemical } \\
\text { Element }\end{array}$ & $\mathbf{C}$ & $\mathbf{C r}$ & $\mathbf{M o}$ & $\mathbf{N i}$ & $\mathbf{M n}$ & $\mathbf{S i}$ & $\mathbf{V}$ & $\mathbf{T i}$ & $\mathbf{C u}$ & $\mathbf{P}$ & $\mathbf{S}$ \\
\hline $\begin{array}{c}\text { SN 924 } \\
\text { Spec }\end{array}$ & $0.17-$ & $1.20-$ & $1.00-$ & $<0.60$ & $\begin{array}{c}0.30- \\
0.50\end{array}$ & $\begin{array}{c}0.30- \\
0.60\end{array}$ & $\begin{array}{c}0.25- \\
0.35\end{array}$ & - & - & $0.035 \mathrm{X}$ & $0.035 \mathrm{X}$ \\
\hline Reported & 0.2 & 1.38 & 1.06 & 0.15 & 0.42 & 0.46 & 0.29 & - & 0.14 & 0.011 & 0.006 \\
\hline Actual & 0.22 & 1.3 & 1.06 & 0.15 & 0.4 & 0.43 & 0.28 & $<0.01$ & 0.14 & $<0.01$ & $<0.01$ \\
\hline
\end{tabular}

Record = value supplied by OEM (vendor), measured = results obtained by laboratory.

Mechanical Behavior. The performance of 21CrMoV5 - 11 is specified in the fourth part of SN 924. The tensile performance test is specified in DIN EN 10002. The minimum value of the impact test at 20 degrees centigrade (68 degrees F) and specified in accordance with DIN EN 10045. Tensile strength and impact tests were performed simultaneously in both longitudinal and transverse directions. For the purpose of brief investigation, only 1 Tensile and 3 impact tests were performed, in a longitudinal (axial) direction, sampling is taken from the outer end of the roller neck. The test sample is intercepted at the radial depth of $1 / 3$ diameter. The test results are not in accordance with the specifications and highlighted in red in Table 6. The yield and tensile strength values are about twice the required value. Elongation is $10 \%$ below the required limit.

In addition, the 3 shock work is below the limit of the Joule required. The average impact energy is $4.5 \mathrm{~J}$, only about $10 \%$ of the inspection requirements. The rate of brittle fracture (intergranular) is $100 \%$, exceeding the requirements of the maximum brittle fracture rate allowed in the inspection of $70 \%$.

Based on historical data, 21CrMoV5- 11 relationship between impact energy and elastic strength is shown in figure 10, the color section is the relation between the impact energy and the elastic strength of the material, the impact of material test Charpy $\mathrm{V}->880 \mathrm{MPa}$, showing a high impact strength range. It is shown in the diagram that the impact energy of 21CrMoV5-11 material is very low at 1236.9 Mpa tensile strength.

Table 6: Performance test results

\begin{tabular}{|c|c|c|c|c|c|}
\hline Project & $\begin{array}{c}\text { Yield Point } \\
\text { (MPa) }\end{array}$ & $\begin{array}{c}\text { Tensile Strength } \\
\text { (MPa) }\end{array}$ & $\begin{array}{c}\text { Elongation } \\
\text { (\%) }\end{array}$ & $\begin{array}{c}\text { Impact Energy } \\
\text { (J) }\end{array}$ & $\begin{array}{c}\text { Hardness } \\
\text { (HV30) }\end{array}$ \\
\hline SN 924 Spec & 540 & $690-830$ & 16 & 42 & $220-265$ \\
\hline Reported & 555 & 735 & 22 & 69 & $230-255$ \\
\hline Actual & $\mathbf{1 1 3 1 . 4}$ & $\mathbf{1 2 3 6 . 9}$ & $\mathbf{6}$ & $\mathbf{2 . 7 , 5 . 4 , 5 . 4}$ & $\mathbf{3 9 0}$ \\
\hline
\end{tabular}

Note: tensile strength at room temperature $\left(20^{\circ} \mathrm{C}\right)$, impact test carried out at $0^{\circ} \mathrm{C}$.

Record = value supplied by OEM (vendor), measured = results obtained by laboratory 
Room Temp. CVN vs. Tensile Strength

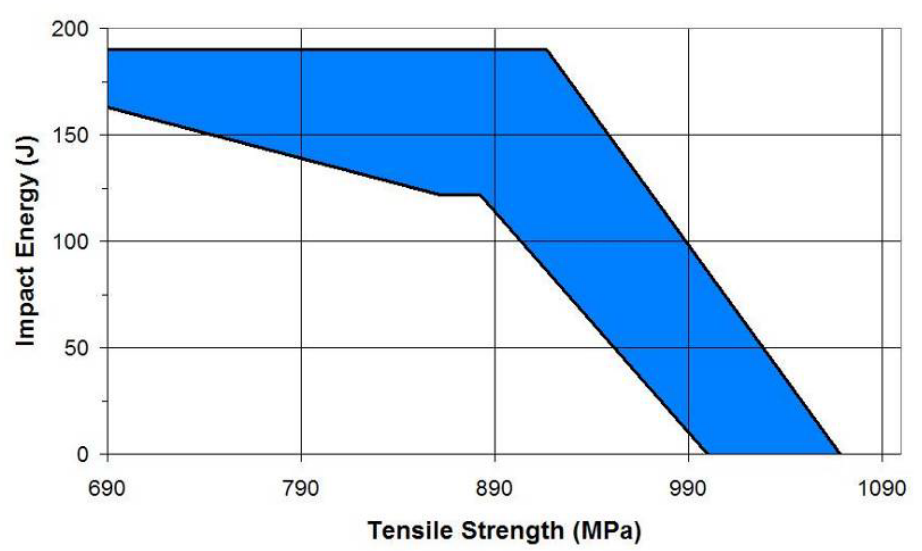

Fig.10. Relationship between impact energy and elastic strength

The test results of hardness, mechanical properties and impact energy are not the condition of 21CrMoV5-11 material quenched and tempered in liquid medium, the results of the roll body and roll neck test are similar to those of 21CrMoV5-11 steel.

Macroscopic Corrosion Test of Roll Neck (test piece). The cuboid specimen is placed in the $\mathrm{HCl}$ hot solution of 50:50 for 10 minutes, etched specimens are shown in Figure 11, the macro etching shows the grain streamlines of the forging roller material, there is no macroscopic discontinuity.

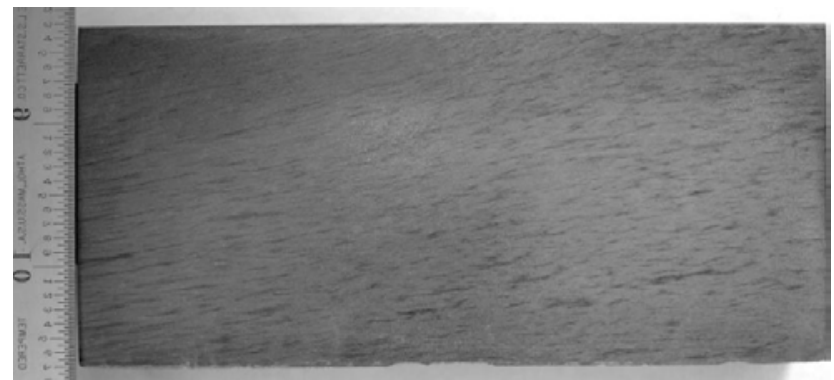

Fig.11. Shaft neck longitudinal macro corrosion test specimen

\section{Testing of Stainless Steel Surfacing}

Hardness of Surfacing Layer in Circumferential Direction. Hardness on the two circumferential directions of the roller surface, radius $75 \mathrm{~mm}$, take points on each circle in turn, it consists of 21 parts (0 to 20). The first area is about $75 \mathrm{~mm}$ in the outer edge of the roller, the second area is in the middle of the roll, the hardness readings near the edge of the roll represent acceptable values for the hardness of the surfacing layer, the hardness of the middle part represents the hardness of the surfacing layer which is affected by the thermal load, the inconsistency of the intermediate hardness will indicate a state of instability in the casting process, the results of the roller edge test confirm that the hardness of the surfacing layer is uniform and is the upper limit of the specified value, roller intermediate test, it is proved that the roller body works in accordance with heat. Hardness from 413 $\mathrm{HV}$ to $307 \mathrm{HV}$ is not abnormal, most important of all, no severe softening zone is shown to prolong the slab stopping and major thermal stress deformation.

Chemical Composition. After testing ingredients, it is proved that the chemical composition of surfacing layer is not consistent with the content of Mo, and the rest conforms to the SN 925 standard.

Macro Etching. The cuboid specimen is placed in the $\mathrm{HCl}$ hot solution of 50:50 for 10 minutes, etched gaskets and typical weld metal are shown in figures 12 and 13, test results proved that there were no discontinuities, close observation shows that the roller has been welded three layers, and the roller surface is in the middle welding layer of third layers, the black corrosion zone in the middle of the first surfacing layer is the parent of the forgings, this case is narrow for solder drop forming, don't think it's harmful. 


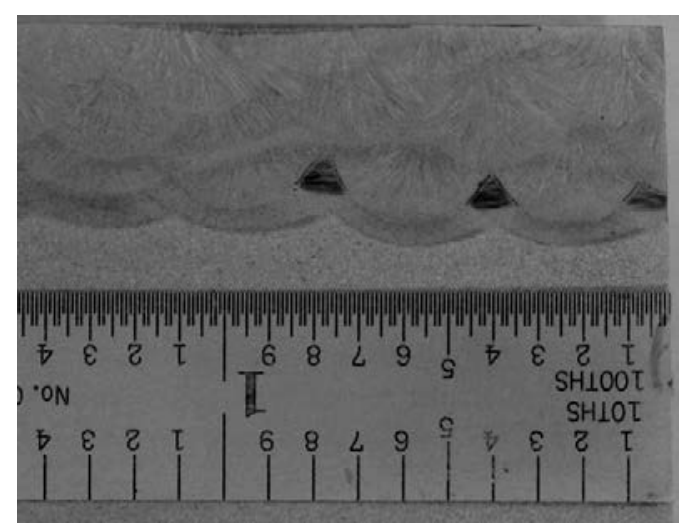

Fig.12. Macro corrosion test piece

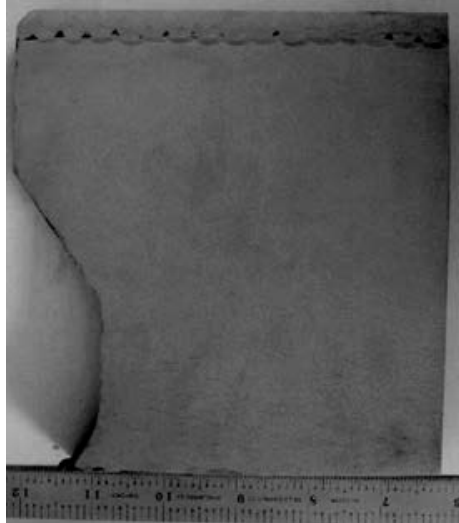

Fig.13. Macroscopic corrosion pattern

\section{Conclusion}

(1) Tensile and yield strength of forgings, the value in the length direction is nearly 2 times that of the SN 924 and fourth parts, the elongation rate is 10\%, smaller than the limit required. The mechanical properties do not show the condition of 21CrMoV5-11 in the quenched and tempered condition. The material shows the condition after quenching, this may be the main reason for the breakage of the roller.

(2) The CVN impact properties of the roll neck at the $1 / 3$ radius are significantly smaller than the minimum required, cause the roller to withstand the vibration of the cold plate during the work, rod insertion, the roller roller clamping pressure generated by the driving and hot straightening bending etc. The brittleness (intergranular) rate of impact test is 100\%, also inconsistent with the regulations, this may also be the main cause of roller breakage.

(3) The transverse hardness test of the roll body and roll neck shows that the depth and direction of the forging are the same as that of the hardness, the hardness ranged from $375 \mathrm{HV}$ to $410 \mathrm{HV}$, exceeding $220 \mathrm{HV}$ to $265 \mathrm{HV}$ required by SN 924 and fourth. This indicates that subsequent tempering has not been carried out to meet the specified requirements, this is also the main cause of roller breakage.

(4) The crack on the roller extends from the longitudinal crack to the whole roll body until the end of the roll neck, this crack indicates a quenching crack or is caused by a severe inconsistency between heating and cooling.

(5) The results of chemical analysis showed that the composition of the roller and surfacing layer met the requirements, however, the content of Mo is slightly different from the requirement, but it is not the cause of the failure of the roller.

\section{References}

[1] Ruitang Liu, Failure analysis of mechanical parts, Harbin Institute of Technology Press, 2003.

[2] Maocai Sun, Mechanical properties of metals, Harbin Institute of Technology Press, 2003.

[3] Ruiyang Chen, Zhiyong Mao, Inspection technology of Mechanical Engineering (Third Edition), Higher Education Press, 2000.

[4] Xinan Feng, Mechanical manufacturing equipment design, Publishing of machinery industry,2004. 